\title{
Figurações identitárias da Irlanda em palcos portugueses
}

\author{
Maria Helena Serôdio
}

\author{
Paulo Eduardo Carvalho, ldentidades \\ reescritas: Figurações da Irlanda no teatro \\ português, Porto, Afrontamento / Instituto \\ de Literatura Comparada Margarida Losa, \\ 2009, 607 pp.
}

Em tempo de facilitismos académicos e consequentes despromoções curriculares que prosperam ao abrigo dos acordos de Bolonha, são de assinalar os trabalhos que, remando contra essa actual viciação, recolocam na dissertação de doutoramento a exigência de uma investigação aprofundada e de uma exegese crítica às matérias a tratar. E esse foi o ponto de partida para este volume que Paulo Eduardo Carvalho agora deu à estampa, depois de o apresentar - como dissertação de doutoramento - à Faculdade de Letras da Universidade do Porto. E nisso a FLUP está de parabéns ao sinalizar para o exterior o tipo de trabalhos académicos que suscita e promove, bem como a elevada qualificação dos seus professores.

Neste caso, porém, uma outra questão se torna evidente ao provar como, no campo dos estudos de teatro (que este trabalho também habita), a investigação - para se cumprir da melhor forma - não dispensa o conhecimento próximo das realidades artísticas a estudar, evitando assim o discurso ex cathedra do observador que permanece no recato do seu puro academismo. De resto, já em 1993, quando Paulo Eduardo Carvalho apresentara a sua tese de Mestrado à Faculdade de Letras da Universidade de Lisboa - A história do território da imaginação: A Irlanda de Brian Friel e Field Day - era já evidente a sua sedução pela consequência a que obriga o texto dramático, pelo que não foi surpresa vê-lo pouco depois - a convite de José Peixoto - envolvido na preparação do espectáculo Traduções, sobre texto de Friel - que entretanto traduzira - e que se apresentou em 1996 no Centro Cultural da Malaposta em encenação de Antonino Solmer.

É público, entretanto, o que tem sido o plural trajecto do tradutor, dramaturgista, crítico de teatro, ensaísta e, mais recentemente, encenador Paulo Eduardo Carvalho - com mais de trinta traduções suas que subiram já à cena - e com uma vasta obra crítica sobre teatro de onde se destacam não apenas os muitos artigos publicados sobre textos, traduções, autores e espectáculos, mas também entrevistas, recensões e conferências. De entre os muitos trabalhos publicados, merece especial destaque, naturalmente, o seu exemplar estudo de grande fôlego, Ricardo Pais: Actos e variedades, saído em 2006 com a chancela da Campo das Letras.

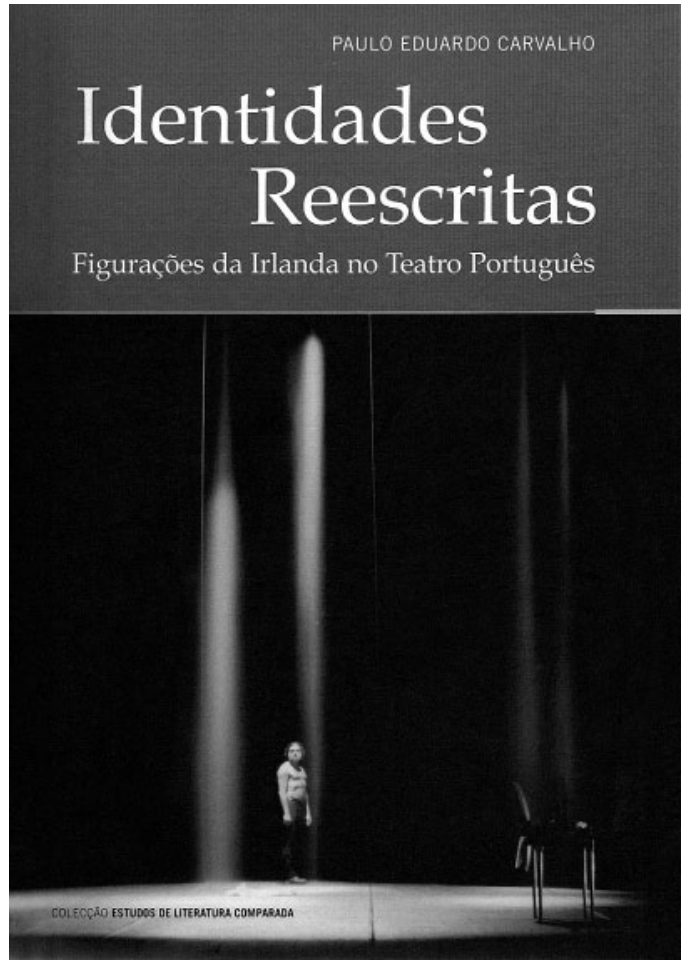

É também notória a sua insaciável curiosidade para averiguar de perto o que se publica em teatro (e sobre teatro) na Irlanda, o centro electivo do seu gosto e devoção, que, todavia, não o dispensa do interesse também pelo teatro inglês e norte-americano, e, enfim, em abono da verdade, pelo italiano (que também traduz) e português, entre, afinal, muitos outros que estuda, traduz, prefacia ou critica. E essas deambulações - sempre acompanhadas de reflexões interrogativas e análises circunstanciadas garantem o apurado olhar crítico e a capacidade interpelativa com que atravessa textos, traduções, realizações cénicas, registos interpretativos e consequências de sentido cultural e político que o contexto teatral imprime às (e recebe das) criações cénicas.

Por todas estas razões - cumulativamente - este estudo constitui por si só um marco importante, decisivo mesmo, do que tem sido a transformação entre nós do pensamento e da escrita sobre teatro. Porque, embora esta obra tenha tido o seu epicentro no espaço universitário, ela revela ser um modelo exemplar que necessariamente se colocará a todos os que hoje desejem estudar o teatro nas suas múltiplas dimensões, atravessando 
necessariamente o campo da criação artística. E que, por isso mesmo, se oferece num efectivo transbordamento de saberes, sentidos e interrogações.

É assim que, com um título que resume todo um programa de estudo - Identidades reescritas: Figurações da Irlanda no teatro português-, este livro compagina o campo dos estudos irlandeses com um alargamento de perspectivas, derivando para novas inquirições, firmando outros nexos, extravasando para distintos contornos disciplinares, respondendo, enfim, a exigências mais vastas da nossa contemporaneidade. Trata-se de equacionar a possivel definição de uma especificidade identitária (em termos "nacionais" da Irlanda), que terá recebido contornos plurais nas várias reformulações tradutórias, dramatúrgicas e cénicas que em Portugal se fizeram. E nessas reescritas discursivas e teatrais estarão presentes formas de posicionamento linguístico, cultural e político que o Autor aqui se propõe apreciar.

Paulo Eduardo Carvalho parte assim de uma problemática que alguns dos mais profundos conhecedores das matérias irlandesas declaram ser incontornável, como é o caso de Christopher Murray:

A identidade é [...] o menos motivador dos temas em termos do sucesso internacional e comercial. E, contudo, por mais entediante que possa ser para os estrangeiros, os irlandeses, devido a legitimas razões históricas, têm de estar sempre a mexer na ferida da identidade nacional. É uma obsessão, da qual tem resultado alguma da nossa melhor literatura (Cit. p. 547)

Ao fazê-lo, Paulo Eduardo Carvalho integra inteligentemente e de forma especular - o que em Portugal será também um factor de contínua perplexidade, só que as mais das vezes denegado. Nesse sentido, é importante ter sinalizado o que foi correspondendo aos tempos políticos que atravessámos desde 1956, altura em que se inaugurou entre nós a atenção à dramaturgia irlandesa em palcos portugueses (de que o autor justamente retira Oscar Wilde e Bernard Shaw), passando pelas últimas três décadas em que o interesse pelas matérias da Irlanda cresceu exponencialmente. Assim, ao longo deste estudo, vão sendo enunciadas e interpeladas as questões da censura anterior ao 25 de Abril de 1974 e as razões mais de ordem estética e cultural que foram marcando as opções tradutórias desde então.

0 livro apresenta-se, pois, como um exercício exaustivo e competente de uma inequívoca multidisciplinaridade, pressupondo pesquisas, saberes, análises e avaliações que atravessam os campos disciplinares da história, da cultura, da literatura dramática, do cinema, dos estudos de recepção, da iconografia, dos estudos de teatro, do comparatismo, dos estudos de tradução e, como é evidente, da história do teatro em Portugal. E vem, felizmente, acompanhado por um importante e expressivo caderno de imagens em extra-texto de 16 páginas, reproduzindo 54 fotografias de espectáculos.

Neste vasto conjunto de parâmetros e particulares requisitos, de que o livro dá prova eloquente de os adoptar e a eles corresponder, não posso deixar de destacar a necessária atenção - e capacidade analítica - ao que se faz hoje em teatro em termos de estéticas professadas, condições de produção, competência interpretativa, a partir das quais Paulo Eduardo Carvalho faz derivar a aferição de sentidos e valores que se manifestam nestas figurações da Irlanda identificadas no teatro português.

$\mathrm{Na}$ organização deste livro, destaca-se um primeiro patamar - a parte primeira - onde se enunciam perspectivas teóricas e históricas num plano mais geral, e uma segunda parte - a mais longa - em que se verifica uma repartição dos autores a estudar por três agrupamentos "geracionais" reportados a significativas metáforas espaciais. É assim que "territórios, urbanidades, ruralidades, aproximações, encontros", são palavras recorrentes. Aparece-nos primeiro o "mundo ocidental" (de Yeats, Synge e O'Casey), depois a "desterritorialização" referida a Samuel Beckett, e, por fim, os "novos mundos" que compreendem as dramaturgias de Brian Friel, Frank McGuiness, Marie Jones, Martin McDonagh, Conor McPherson e Mark O'Rowe, entre outros.

Desta forma, e numa feliz intercepção de espacialidades e cronologias, o livro joga, de forma inteligente, numa contaminação possivel da matéria das figurações de que trata.

É também relevante o facto de se estabelecer um razoável equilíbrio entre as páginas dedicadas a cada autor - na estratégia de amostragem que adoptou - e, no caso de Beckett, a opção por focalizar a peça que teve maior fortuna tradutória e cénica em Portugal: Waiting for Godot.

0 estudo comparado, a que procede, não apenas revela uma apreciável finura de análise, como se apresenta com uma salutar intenção "pedagógica" no que diz respeito ao tipo de apreciação crítica que faz das estratégias de tradução. Estas apresentam-se em termos de uma oposição: de um lado do eixo, a "aculturação" (ou seja: domesticação, assimilação, eclipse de alteridade, etc.), do 
outro, a tradução distanciadora, resistente, estrangeirante Mollysweeney, (cito de várias páginas e em contextos e formulações de Brian Frield, enc. Nuno Carinhas, Ensemble Sociedade de Actores, 1999 (Emilia Silvestre) fot. João Tuna. teóricas diferenciadas). Estas são questões cruciais para definir as opções em confronto (ou em alternativa) e que se tornam visiveis em culturemas (p. 23) como: a localização geográfica (os topónimos, por exemplo), os conceitos políticos, as realidades históricas, os sistemas de crenças, os universos artísticos, as especificidades do quotidiano, os idiolectos, etc. Enfim, aquilo que Paulo Eduardo Carvalho identifica como sendo as formas de negociação da "alteridade", ou seja, da reconfiguração textual e cénica dessa Irlanda - que os dramaturgos irlandeses enunciaram - mas que é refeita entre nós pelo tradutor, pelos criadores em cena (encenador, cenógrafo, figurinista, músico...), pelos actores em palco, pela crítica publicada e mesmo pela recepção do público. E esse é um campo que o autor percorre minuciosamente e que analisa nos seus efeitos e consequências para refigurar a Irlanda em português.

A deambulação por estes territórios dramáticos permite também articular "histórias" (da História da Irlanda e de Portugal), usando um acervo de informação que integra uma vasta bibliografia nacional e internacional - que é aqui convocada, escrutinada e avaliada com indiscutivel pertinência -, e a que adiciona uma listagem de espectáculos feitos em Portugal sobre autores irlandeses, bem como dados recolhidos na Torre do Tombo (do espólio das actividades censórias do Estado Novo), no Museu Nacional do Teatro, em arquivos diversos, junto de companhias e de teatros, em periódicos, mas que não dispensou também a interpelação directa a fazedores de teatro.

E este é um valor acrescentado à reflexão que o livro organiza: pensar e escrever sobre teatro, com a experiência de quem sabe também estar do lado dos fazedores, num protestado e assumido agenciamento artístico e teatral: na tradução de peças (e já são muitas as que assegurou e que felizmente, em grande parte, têm sido publicadas), na consultoria dramatúrgica junto de companhias, no acompanhamento (e realização) de encenações, na interpelação crítica a criadores, entre outras tarefas a que não se exime.

E ao fazê-lo, o estudo, que apresenta, consegue - a meu ver - conciliar o rigor conceptual (de quem conhece a teoria e a sua reformulação "no terreno" teatral) e a consistência argumentativa. Para além dessa indefective competência, há ainda a assinalar neste livro um estilo claro, que se torna acessivel mesmo a leitores não especializados.

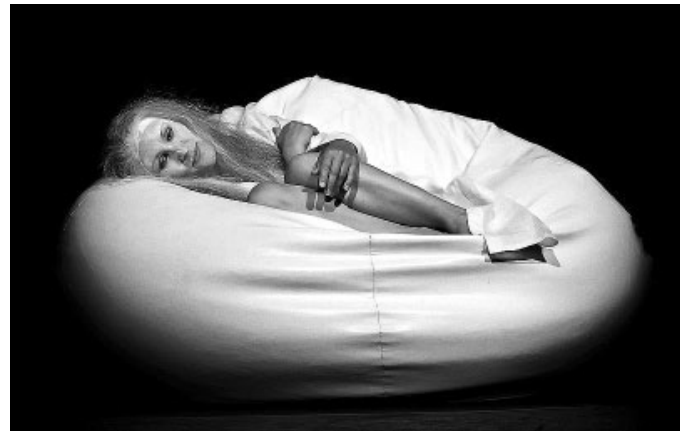

Pelo seu protagonismo no estudo e reflexão sobre a dramaturgia irlandesa quer do ponto de vista da tradução, quer do ponto de vista da sua refracção em palcos portugueses, Paulo Eduardo Carvalho presta a todos nós - que gostamos de teatro e nos preocupamos com a cultura e o teatro portugueses - um serviço louvável por aquilo que nos traz daquele outro território que ele prova tão bem conhecer nos seus contornos geográficos, históricos e simbólicos.

Pelo que termino citando Nicholas Grene da p. 545 deste livro:

Pode acusar-se a dramaturgia irlandesa de ser antiquada, palavrosa conduzida por fórmulas, propagando as suas imagens da Irlanda como uma espécie de turismo cultural para os mercados interno e de exportação (...) [mas] no contexto da cada vez maior mesmidade do capitalismo global e do vazio da postura pós-modernista, a dramaturgia irlandesa, na sua diferença ostensiva e na intensidade do seu empenhamento político, ainda se mostra capaz de produzir verdadeiros efeitos teatrais.

E julgo perceber neste livro de Paulo Eduardo Carvalho um efeito paralelo no que diz respeito ao estudo do teatro aqui ou em qualquer outro lugar do mundo em que o teatro seja valorizado e aceite como uma importante respiração cultural e artística que configure uma identidade colectiva. Porque o teatro, ainda que habitado por contradições e conflitos, aponta para - e consubstancia na pluralidade das suas articulações gregárias - aquele que é o nosso horizonte humano. Que o autor soube aqui interpelar de forma atenta e cativante. 